\title{
Socio-Economic Status and Hemoglobin Concentration of Type 2 Diabetes Mellitus Patients Attending Diabetic Clinic in Benin City, Nigeria
}

\author{
Alfred Friday Ehiaghe ${ }^{1,2,3}$, Joy Imuetinyan Ehiaghe ${ }^{2,3}$, Ositadinma Martin Ifeanyichukwu ${ }^{3}$, \\ Ikusemoro Augustina Isioma ${ }^{1}$, Justus A. Ize-Iyamu ${ }^{4}$, Lily O. Ize-Iyamu ${ }^{4}$ \\ ${ }^{1}$ Department of Hematology, College of Health Sciences, Igbinedion University, Okada, Nigeria; ${ }^{2}$ Lahor Research and Medical Cen- \\ tre, Benin City, Nigeria; ${ }^{3}$ Department of Medical Laboratory Science, Nnamdi Azikiwe University, Awka, Nigeria; ${ }^{4}$ Pathology De- \\ partment, Central Hospital, Benin City, Nigeria. \\ Email: fredleo2547@yahoo.com, Ehiaghejoy@yahoo.com, ositadinma@yahoo.com, isiotyn@yahoo.com, \\ justize4ever09@yahoo.com, lijiggs@gmail.com
}

Received July $13^{\text {th }}, 2013$; revised August $13^{\text {th }}, 2013$; accepted August $31^{\text {st }}, 2013$

Copyright (C) 2013 Alfred Friday Ehiaghe et al. This is an open access article distributed under the Creative Commons Attribution License, which permits unrestricted use, distribution, and reproduction in any medium, provided the original work is properly cited.

\begin{abstract}
The aim of this study is to determine the Socio Economic Status and Red Blood Cell Hemoglobin concentration alteration in type 2 Diabetes mellitus patients attending Diabetic Clinic in Benin City, Nigeria. The sample population consists of 142 subjects, 71 of patients were known in Type 2 Diabetes mellitus already on drugs and were confirmed to be Diabetic using Glucose oxidase method while the other 71 subjects were age matched apparently healthy control subject on routine check up, they were confirmed to be non Diabetic using the Glucose oxidase method. Hemoglobin concentrations were done using the Cyanmethemoglobin method. Those under the low income Socio-Economic status had the highest incidence of type 2 Diabetes mellitus (49\%) of the Diabetic population, closely followed by the middle income Socio-Economic status (35\%) of the Diabetic populations. The Mean \pm S.D of Hemoglobin concentration of control subjects against Mean \pm S.D of Hemoglobin concentration of the various Socio-Economic status of Males and Females type 2 Diabetes mellitus patient show a statistically significant decrease $(\mathrm{P}<0.05)$. Type 2 Diabetes mellitus is associated with Anemia irrespective of Socio-Economic status. Prevention of the Global Diabetes epidemic must include regular national surveys, introduction of Diabetes health education in schools, emphasis on balance diet, regular exercise and abstention from tobacco smoking.
\end{abstract}

Keywords: Anemia; Hemoglobin Concentration; Ascaris Lumbricoides; Hookworm; Cyanmethaemoglobin Method

\section{Introduction}

The prevalence of type 2 Diabetes mellitus has been rapidly rising worldwide. It is caused by either deficiency of insulin secretion or reduction in the biology effectiveness of insulin [1]. The International Diabetes Federation (IDF) estimated in 2011 that 366 million adults, aged 20 - 79 years, of the world's 7 billion population have Diabetes mellitus. This gives a comparative prevalence of $8.5 \%$. Since more than $90 \%$ of the global cases of Diabetes are type 2 , it is evident that the epidemic is mainly due to the escalation of causes of type 2 Diabetes mellitus [2-6]. Significant socio-economic gradients have been shown in the prevalence of several cardiovascular disease risk factors, including diabetes mellitus. Diabetes may be up to two times more prevalent in low income population. According to the current definition, two fasting glucose measurement above $126 \mathrm{mg} / \mathrm{dl}[7.0 \mathrm{mmol} / \mathrm{l})$ is considered diagnostic for Diabetes mellitus or Glycated hemoglobin [HbA1C) above 6.5\% [7,8]. Nigeria with less than $5 \%$ health insurance presents a difficult picture for its 3.1 million people with Diabetes, the highest in Africa $[9,10]$. The country has a population of about 150 million, of which 76 million are adults. Diabetes related death in Nigeria in 2011 accounted for 63,340 people [11]. The classical symptoms of Diabetes are polydipsia, polyuria and weight loss, and the causes of most type of diabetes are multi-fictional environmental, lifestyle and genetic factors are involved $[2,3,12]$.

Anemia is relatively common in patients with Diabetes mellitus, it contributes to many clinical aspects of Diabetes mellitus including cardiovascular mortality and chronic kidney disease [13]. Anemia is defined by the 
World Health Organization as a hemoglobin concentration below the following threshold, children ( $5-12$ years) $<11.5 \mathrm{~g} / \mathrm{dl}$, teens $(12-15$ years $)<12.0 \mathrm{~g} / \mathrm{dl}$, Women $(>15$ years) $<12.0 \mathrm{~g} / \mathrm{dl}$ and Men $(>15$ years $)<13 \mathrm{~g} / \mathrm{dl}$.

Generally, Anemia in chronic disease like Diabetes mellitus and Tuberculosis are normocytic normochromatic type, although in a few cases, microcytosis and hypochromia also occur [14].

This study was conducted to determine the Socio Economic status and Red blood cell hemoglobin concentration alteration in type 2 Diabetes mellitus patients attending a Diabetic clinic in Benin City, Nigeria.

\section{Materials and Methods}

\subsection{Study Design}

A cross sectional laboratory based, analytical survey was adopted for this research.

\subsection{Study Area}

This study was carried out in Benin City, Edo State, Nigeria. The two Hospital used were Orobosa Medical Centre and Lahor Medical Centre in Benin City.

\subsection{Sample Size Determination}

The sample size were determined using the formula [15]. $\mathrm{N}=\mathrm{Z}^{2} \times \mathrm{P}(1-\mathrm{P}) / \mathrm{d}^{2}$.

$\mathrm{d}=$ desired level of significance $(0.05)$.

$\mathrm{Z}=$ Confidence internal (1.96).

$\mathrm{P}=$ prevalence rate $(4.9 \%)$ [11].

Using this formula, the minimum number of sample will be 71 subjects.

\subsection{Subjects}

The sample population consists of 142 subjects. 71 of patient were known Type 2 Diabetes mellitus already on drugs and were confirmed to be Diabetic using glucose oxidase method [16]. While the other 71 were age matched apparently healthy control subject on routine checkup, they were confirmed to be non diabetic using the glucose oxidase method. Approval and patient consent was obtained from the two centers. Those that have access to better dietary habits, health conditions, improved education and income were classified as high Socio-Economic status, while the middle and low socio-economic status were classified with the absence of one or more criteria as listed above.

\subsection{Inclusion Criteria}

Both males and females were included in this study.

\subsection{Exclusion Criteria}

Subjects diagnosed with other systemic diseases will be excluded from this study.

\subsection{Collection of Blood Samples}

$10 \mathrm{ml}$ of venous blood was collected from the medial cubital vein using vacutainer and needle from each of the subjects and shared equally into an Ethylene Diamine tetra acetic acid (EDTA) container and Sodium FluoridePotassium Oxalate container.

\subsection{Blood Sample Processing}

Sample Preparation and test performance for Hemoglobin concentrations were done using the Cyanmethemoglobin method described by [17]. $20 \mu \mathrm{l}$ of blood was diluted in a $5 \mathrm{ml}$ buffered solution of potassium Cyanide to yield the stable hemoglobin derivative cyanmethemoglobin. The potassium ferricyanide converts the Hemoglobin to methemoglobin by the action of potassium cyanide. This must be allowed to stand for at least three minutes, to allow for complete conversion of Hemoglobin to cyanmethemoglobin, before the absorbance is measured against a Reagents blank at a wavelength of $540 \mathrm{~mm}$ using a spectrophotometer.

\subsection{Blood Glucose Determination}

\subsubsection{Reagent Composition \\ R1a (Buffer) Phosphate Buffer $\quad 0.1 \mathrm{~mol} / 1, \mathrm{pH} 7.0$ Phenol $11 \mathrm{mmol} / \mathrm{l}$ \\ R1b (GOD-PAP Reagent) \\ 4 aminophenazone $\quad 0.77 \mathrm{mmol} / \mathrm{l}$ \\ Glucose Oxidase $\quad \geq 1.5 \mathrm{kU} / \mathrm{l}$ Peroxidase $\quad \geq 1.5 \mathrm{kU} / 1$}

Preparation of working Reagent (Reagent 1).

Reconstitute the content of one vial of reagent $\mathrm{R} 1 \mathrm{~b}$ with the entire portion of Buffer R1a. The working reagent is stable for 3 months at $+2^{\circ} \mathrm{C}$ to $+8^{\circ} \mathrm{C}$.

\subsubsection{Procedure (Semi Micro Method)}

$10 \mu \mathrm{l}$ of the standard or test sample was added to $1000 \mu \mathrm{l}$ of Reagent 1 , mixed and incubated for 25 minutes at $15^{\circ} \mathrm{C}-20^{\circ} \mathrm{C}$. The absorbance of the standard and the sample was measured against the Reagent blank within 60 minutes at a wavelength of $540 \mathrm{~mm}$ using a Spectrophotometer.

\subsubsection{Study Duration}

Sample collection and processing was from March 2010 to June 2010.

\section{Limitation of the Study}

Subject compliance to Blood samples collection was the limitation to this study. 


\subsection{Data Collection}

Data was collected using self administered semi structure questionnaire.

\subsection{Statistical Analysis}

All numerical results were collated from the four groups. Data were presented as Mean \pm Standard Deviation (S.D) and analyzed using one way analysis of variance (ANOVA). Using SPSS version 18.0 P values $<0.05$ were considered significant.

\section{Results}

Of the 142 subject enlisted for the study, 80 (56\%) were Males and 62 (44\%) were Females. The age group that has the highest number of type 2 Diabetes mellitus was $41-50$ (64\% of Males and $36 \%$ of the Females). Closely followed by $31-40(50 \%$ of the Males and $50 \%$ of the Females), Table 1.

Those under the low income Socio-Economic status had the highest incidence of type 2 Diabetes mellitus (49\%) of the Diabetic population, closely followed by the middle income Socio-Economic status (35\%) of the Diabetic populations, Tables 2 and 3.

Table 4 shows the Mean \pm S.D of Blood Glucose level of control subjects against Mean \pm S.D of Blood Glucose level of the various Socio-Economic statuses of males and female control patient, showing a statistically significant increase $(\mathrm{P}<0.05)$.

Table 5 shows the Mean \pm S.D of Hemoglobin concentration of control subjects against Mean \pm S.D of Hemoglobin concentration of the various Socio-Economic statuses of males and female type 2 Diabetic mellitus patient, showing a statistically significant decrease $(\mathrm{P}<0.05)$.

\section{Discussion}

Our study revealed that age group that had the highest number of type 2 Diabetes mellitus was $41 \%-51 \%$ of

Table 1. Age, sex and type 2 diabetes mellitus (Dm) distribution.

\begin{tabular}{ccccccc}
\hline $\begin{array}{c}\text { Age } \\
\text { range } \\
\text { (yrs) }\end{array}$ & Subjects & Males & Females & $\begin{array}{c}\text { Type 2 } \\
\text { Dm }\end{array}$ & $\begin{array}{c}\text { Type 2 } \\
\text { Dm male } \\
\text { (\%) }\end{array}$ & $\begin{array}{c}\text { Type 2 } \\
\text { (\%) }\end{array}$ \\
\hline $15-20$ & 10 & 6 & 4 & 5 & $3(60)$ & $2(40)$ \\
$21-30$ & 32 & 15 & 17 & 11 & $5(45)$ & $6(55)$ \\
$31-40$ & 30 & 16 & 14 & 8 & $4(50)$ & $4(50)$ \\
$41-50$ & 40 & 25 & 15 & 28 & $18(64)$ & $10(36)$ \\
$\geq 50$ & 30 & 18 & 12 & 19 & $10(53)$ & $9(47)$ \\
Total & $\mathbf{1 4 2}$ & $\mathbf{8 0}(\mathbf{5 6})$ & $\mathbf{6 2}(\mathbf{4 4 )}$ & $\mathbf{7 1}$ & $\mathbf{4 0 ( 5 6 )}$ & $\mathbf{3 1 ( 4 4 )}$ \\
\hline
\end{tabular}

Table 2. Shows socio-economic status of type 2 Diabetes mellitus subjects.

\begin{tabular}{ccc}
\hline & Socio-economic status & Diabetes mellitus population (\%) \\
\hline $\mathrm{P}$ & High income status & $11(16)$ \\
$\mathrm{Q}$ & Middle income status & $15(21)$ \\
$\mathrm{R}$ & Low income status & $45(63)$ \\
& Total & $\mathbf{7 1}$ \\
\hline
\end{tabular}

Table 3. Shows socio-economic status of control subjects.

\begin{tabular}{ccc}
\hline & Socio-economic status & Control subject (\%) \\
\hline $\mathrm{P}$ & High income status & $15(21)$ \\
$\mathrm{Q}$ & Middle income status & $20(28)$ \\
$\mathrm{R}$ & Low income status & $36(51)$ \\
& Total & $\mathbf{7 1}$ \\
\hline
\end{tabular}

the Males and $36 \%$ of the Females, Closely followed by $31-40$ (50\% of the Males and $50 \%$ of the Females), Table 1. These may be due to that type 2 Diabetes mellitus is common among the age bracket. These have been reported by these Authors. The International Diabetes Federation (IDF) estimated in 2011 that 366 million adult's age $20-79$ years, of the world's 7 billion population have Diabetes mellitus. This gives a comparative prevalence of $8.5 \%$. Since more than $90 \%$ of the global cases of diabetes are type 2, it is evident that the epidemic is mainly due to the escalation of the cases of type 2 Diabetes mellitus and up to $50 \%$ of cases of Gestational diabetes may end up as type 2 diabetes [2-6].

Those under the low and middle socio-economic status that the highest incidence of type 2 Diabetes mellitus, $49 \%$ and $35 \%$ respectively, Table 2 . This group of subjects falls under the low income earner. Majority of them may be poor and under nourished. This is in line with these findings. Diabetes mellitus has been linked to $\mathrm{Tu}-$ berculosis, HIV/AIDS, Malaria, Poverty, Malnutrition, Cancer, Chronic respiratory diseases and cardiovascular disease. It is very significant that the UN has accorded Diabetes mellitus a right of place as a global jeopardy and chronic killer $[18,19]$.

Table 5, revealed that irrespective of Socio-Economic status, type 2 Diabetes mellitus is associated with a low Hemoglobin concentration $(\mathrm{P}<0.05)$. A decrease in Hemoglobin concentration may be due to the increase in cytokine production occasioned by increased Susceptibility to infection, decrease Erythropoietin (Epo) production associated with increase susceptibility of the kidney to nephropathy seen in type 2 Diabetes mellitus subject and increased generation of free radical occasioned by the Hyperglycemia present in type 2 Diabetes mellitus 
Table 4. Shows the mean \pm S.D of blood glucose level of control subjects against various socio-economic status (P, Q and R) of patients with type 2 diabetes mellitus.

\begin{tabular}{ccccc}
\hline \multirow{2}{*}{ Subjects } & Controls & \multicolumn{3}{c}{ Socio-economic status } \\
\cline { 3 - 5 } & & $\mathbf{P}$ & $\mathbf{Q}$ & $\mathbf{R}$ \\
\hline & $($ Mean \pm S.D $)$ & $($ Mean \pm S.D $)$ & $($ Mean \pm S.D $)$ & $($ Mean \pm S.D $)$ \\
Males & $(\mathrm{g} / \mathrm{dl})$ & $(\mathrm{g} / \mathrm{dl})$ & $(\mathrm{g} / \mathrm{dl})$ & $(\mathrm{g} / \mathrm{dl})$ \\
$\mathrm{n}=71$ & $\mathrm{n}=11$ & $\mathrm{n}=15$ & $128 \pm 0.05^{\mathrm{x}}$ & $129 \pm 0.03^{\mathrm{x}}$ \\
Females & $83 \pm 0.03$ & $129 \pm 0.02^{\mathrm{x}}$ & $132 \pm 0.03^{\mathrm{x}}$ & $142 \pm 0.02^{\mathrm{x}}$ \\
\hline
\end{tabular}

$\mathrm{P}=$ High income status, $\mathrm{Q}=$ Middle income status. $\mathrm{R}=$ Low income status. All numerical result was collated from the four groups. Data is presented as. Mean \pm Standard Deviation (S.D) and analyzed using one way analysis of variance (ANOVA). Using SPSS version $18.0 \mathrm{P}$ values $<0.05$ were considered significant. $\left({ }^{\mathrm{x}}=\mathrm{P}<0.05\right)$.

Table 5. Shows the mean \pm S.D of hemoglobin concentration of control subjects against various socio-economic status (P, $Q$ and $R$ ) of patients with type 2 diabetes mellitus.

\begin{tabular}{ccccc}
\hline \multirow{2}{*}{ Subjects } & Controls & \multicolumn{3}{c}{ Socio-economic status } \\
\cline { 3 - 5 } & & $\mathbf{P}$ & $\mathbf{Q}$ & $\mathbf{R}$ \\
\hline & $($ Mean \pm S.D $)$ & $($ Mean \pm S.D $)$ & $($ Mean \pm S.D $)$ & $($ Mean \pm S.D $)$ \\
Males & $(\mathrm{g} / \mathrm{dl})$ & $(\mathrm{g} / \mathrm{dl})$ & $(\mathrm{g} / \mathrm{dl})$ & $\mathrm{g} / \mathrm{dl})$ \\
$\mathrm{n}=71$ & $\mathrm{n}=11$ & $\mathrm{n}=15$ & $9.1 \pm 0.02^{\mathrm{x}}$ \\
Females & $15 \pm 0.04$ & $9.5 \pm 0.02^{\mathrm{x}}$ & $8.3 \pm 0.01^{\mathrm{x}}$ & $8.0 \pm 0.02^{\mathrm{x}}$ \\
\hline
\end{tabular}

All numerical result was collated from the four groups. Data is presented as mean \pm standard deviation (S.D) and analyzed using one way analysis of variance (ANOVA). Using SPSS version 18.0 P values $<0.05$ were considered significant $\left({ }^{\mathrm{x}}=\mathrm{P}<0.05\right)$.

patient. This is in accordance with these findings. Anemia is relatively common in patients with type 2 Diabetes mellitus and the low hemoglobin concentration contribute to many clinical complication of Diabetes mellitus and is associated with a more rapid decline in Glomerular filtration [20]. Diabetic nephropathy and diabetic retinopathy result in increased susceptibility to low hemoglobin level [21]. A low hemoglobin level is associated with cardiovascular mortality and chronic kidney disease (CKD) in patients with Diabetes mellitus [22]. One of the most potent causes of suboptimal response to Epo is chronic and overt inflammation associated with an increased production of cytokines, such as tumor necrosis factor alpha, interleukin one and interferon gamma which might suppress erythrocyte stem cell proliferation [23-26]. Early Epo deficiency occurs in both type 1 and type 2 Diabetics, although, the prevalence is higher in type 2 diabetes mellitus [27]. The onset of anemia in patients with Diabetes mellitus is caused by severe symptomatic autonomic neuropathy causing efferent sympathetic denervation of the Kidney and loss of appropriate erythropoietin (Epo) production due to damage to the renal interstitial. It has been shown that a Normochromic, Normocytic anemia can occur before evidence of renal im- pairment [28,29].

\section{Conclusion}

Type 2 Diabetes mellitus is associated with anemia irrespective of socio-Economic status. Prevention of the global Diabetes epidemic must include regular national surveys, introduction of Diabetes health education in schools, emphasis on balance diet, regular exercise and abstention from tobacco smoking. This should be accompanied by regular Blood pressure check, Serum lipids and Renal function test monitoring.

\section{REFERENCES}

[1] D. Hansen, P. L. Dendale, M. Beelen, A. Jonkers, A. Mullens and L. Coruy, "Plasma Adipokine and Inflammatory Marker Concentrations Are Altered in Obese, as Opposed to Non-Obese, Type 2 Diabetes Patients," European Journal of Applied Physiology, Vol. 109, No. 3, 2010, pp. 397-404.

[2] International Diabetes Federation, "Diabetes Atlas," 5th Edition, 2011.

[3] World Health Organization, "Expert Committee on the Diagnosis and Classification of Diabetes Mellitus: Report 
on the Diagnosis and Classification of Diabetes Mellitus," Diabetes Care, Vol. 20, 1997, pp. 1183-1197.

[4] World Health Organization, "Expert Committee on the Diagnosis and Classification of Diabetes Mellitus. Follow up Report on the Diagnosis of Diabetes Mellitus," Diabetes Care, Vol. 26, No. 11, 2003, pp. 3160-3167. http://dx.doi.org/10.2337/diacare.26.11.3160

[5] S. Chinenye, D. I. Uchenna, C. N. Unachukwu, A. O. Ogbera and A. C. Ojule, "The Pattern of Diabetes Mellitus in Rivers State, Nigeria," Nigerian Endocrine Practice, Vol. 2, 2008, pp. 87-93.

[6] A. A. Motala, "Diabetes Trends in Africa," Diabetes/ Metabolism Research and Reviews, Vol. 18, Suppl. 3, 2002, pp. 514-520.

[7] S. Vigan, "Type 2 Diabetes," Annals of Internal Medicine, Vol. 152, No. 5, 2010, p. 31.

[8] S. H. Sayolah, M. Miret, J. Sung, C. Varas, D. Gause and F. L. Brancati, "Post Challenge Hyperglycemia and Mortality in a National Sample of U.S Adults," Diabetes Care, Vol. 24, No. 8, 2001, pp. 1397-1402.

[9] A. Osibogun, "The Medicine for Poverty: An Argument for Health and Development. The Ninth Sir Samuel Manuwa Lecture," 36th Annual General and Scientific Meeting, West African College of Physicians (Nigeria Chapter), Uyo, 2012.

[10] "Health Report," WHO Regional Office, WHO, Brazzaville, 2006.

[11] O. O. Ainkugbe, "Non Communicable Disease in Nigeria: National Survey (Final Report) on Hypertension, Coronary Heart Disease, Diabetes Mellitus Hemoglobinopatheis, GGPD Deficiency and Anemia. National Expert Committee on Non-Communicable Disease," Federal Ministry of Health and Social Services, Lagos, 1997.

[12] A. A. Motala, T. Esterhrizen and E. Gouwa, "Diabetes and Other Disorders of Glycaemia in a South African Community: Prevalence and Associated Risk Factor," Diabetes Cares, Vol. 31, No. 9, 2008, pp. 1783-1788.

[13] K. Rossing, P. K. Christensen, P. Hovind, L. Tarnow, P. Rossing and H. H. Parving, "Progression of Nephropathy in Type 2 Diabetic Patients," Kidney International, Vol. 66, No. 4, 2004, pp. 1596-1605. http://dx.doi.org/10.1111/j.1523-1755.2004.00925.x

[14] World Health Organization, "Worldwide Prevalence of Anemia," WHO, Geneva, 2008.

[15] L. Naing, T. Winn and B. N. Rusli, "Practical Issues in Calculating the Sample Size for Prevalence Studies," Archives of Orofacial Sciences, Vol. 1, 2006, pp. 9-14.

[16] D. Barham and P. Trinder, "An Improved Colour Reagent for the Determination of Blood Glucose by the Oxidase System," Analyst, Vol. 97, 1972, pp. 142-145. http://dx.doi.org/10.1039/an9729700142

[17] J. Dacis and D. Lewis, "Practical Hematology," 8th Edition, Churchill Livingstone, London, 2006, pp. 27-30.

[18] K. G. Alberti, P. Zimmet and I. Shaw, "International Dia- betes Federation: A Consensus on Type 2 Diabetes Prevention," Diabetes Medicals, Vol. 24, No. 5, 2007, pp. 451-468.

http://dx.doi.org/10.1111/j.1464-5491.2007.02157.x

[19] Diabetes Care and Research in Europe, "The Saint Vincent. Declaration," Diabetic Medicals, Vol. 7, 1990, p. 360.

http://dx.doi.org/10.1111/j.1464-5491.1990.tb01405.x

[20] World Health Organization, "Prevalence of Diabetes Mellitus. Report of a WHO Study Group,” WHO, No 844. 1994.

[21] K. Rossing, P. K. Christensen, P. Hovind, et al., "Progression of Nephropathy in Type 2 Diabetic," Kidney International, Vol. 66, 2004, pp. 1596-1605. http://dx.doi.org/10.1111/j.1523-1755.2004.00925.x

[22] P. K. Ranil, R. Raman and S. R. Rachepalli, "Anemia and Diabetic Retinopathy in Type 2 Diabetes Mellitus," Journal of Association of Physicians India, Vol. 58, 2010, pp. 91-94.

[23] J. P. New, I. Aung and P. G. Baker, "The High Prevalence of Unrecognized Anemia in Patients with Diabetes and Chronic Kidney Disease: A Population Based Study," Diabetes Medicine, Vol. 25, No. 5, 2008, pp. 564-569. http://dx.doi.org/10.1111/j.1464-5491.2008.02424.x

[24] D. R. Bosman, C. A. Osborn, J. T. Marsden, I. C. Macdougall, W. N. Gardner and P. Watkins, "Erythropoietin Response to Hypoxia in Patients with Diabetic Autonomic Neutropathy and Non Diabetic Chronic Renal Failure," Diabetic Medical, Vol. 19, No. 1, 2002, pp. 65-69. http://dx.doi.org/10.1046/j.1464-5491.2002.00634.x

[25] G. A. Kaysen, "The Microinflammatory State in Uremia: Causes and Potential Consequences," Journal of the American Society of Nephrology, Vol. 12, 2001, pp. 15491557.

[26] M. Goicoechea, J. Martin, P. De Sequera, J. A. Qunoga, A. Ortiz, V. Carreno and C. Caramelo, "Role of Cytokines in the Response to Erythropoietin in Hemo Dialysis Patients," Kidney International, Vol. 54, No. 4, 1998, pp. 1337-1343. http://dx.doi.org/10.1046/j.1523-1755.1998.00084.x

[27] E. O. Zanjani, P. B. McGlave, S. F. Davies, M. Banisadre, M. E. Caplan and G. A. Sarosi, "In Vitro Suppression of Erythropoiesis by Bone Marrow Adherent Cells from Some Patients with Fungal Infection," British Journal of Hematology, Vol. 50, No. 3, 1998, pp. 479-490.

[28] D. R. Bosman, A. S. Winkler, J. T. Marsden, I. C. Macdousall and P. J. Watkins, "Anemia with Erythropoietin Deficiency Occurs Early in Diabetic Nephropathy," Diabetes Care, Vol. 24, No. 3, 2001, pp. 495-499. http://dx.doi.org/10.2337/diacare.24.3.495

[29] J. C. Kathrine, D. W. Joh, G. R. Stephen, S. Hilary, R. O. David, W. Debbie, C. Ivor and O. P. Aled, "Anemia and Diabetes in the Absence of Nephtropathy," Diabetes Care, Vol. 28, No. 5, 2005, pp. 1118-1123. 